\title{
ELECTROCARDIOGRAPHIC MONITORING DURING UPPER GASTRO-INTESTINAL ENDOSCOPY IN YOUNG MEN
}

\author{
MAJ B HANNIGAN, MA, MRCP, RAMC \\ CAPT D MORGAN, SRN, RCNT, RAMC \\ British Military Hospital, Rinteln
}

SUMMARY: Seventy-four men between the ages of 18 and 39 years (mean age 25.8 years) undergoing gastro-intestinal endoscopy were electrocardiographically monitored in order to ascertain whether significant cardiac arrhythmias occurred during the procedure.

Sinus bradycardia was noted in six patients (8-1 per cent) during intubation and ventricular ectopics were noted in one patient. These changes were not considered to be significant.

\section{Introduction}

The various methods of examination of the gastro-intestinal tract are not without hazards. The British Society for Digestive Endoscopy (BSDE) Study (1972) found the incidence of complications of upper gastro-intestinal endoscopy to be one in nine hundred examinations. Cardiac arrhythmias have been noted during examinations with the rigid endoscope at oephagoscopy, during barium enema examinations and during sigmoidoscopy. Bennet ${ }^{1}$ reviews these and quotes a study which gives figures for cardiac arrhythmias during upper gastro-intestinal endoscopy of 82 per cent in patients with ischaemic heart disease and 48 per cent in patients with normal hearts. In the 1972 BSDE study there were five serious cardiovascular complications in the group, including three deaths, but these may not have been related to the actual endoscopic procedure.

In view of these figures it was considered worthwhile to study the incidence of electrocardiograph (ECG) abnormalities in young men undergoing gastro-intestinal endoscopy.

\section{Patients and methods}

The seventy-four patients included in the series were attending routine endoscopy sessions. The majority ( 89 per cent) were being assessed for duodenal ulcer disease. One of the authors (DM) was responsible for placing the electrodes (Vtrace chloride electrodes) and monitoring was performed using the Royal Air Force patient monitoring system (PMS Type 5). The ECG pattern was observed throughout the procedure and rhythm strips were taken of any abnormalities noted for later analysis.

Local anaesthetic spray (Xylotox, equivalent to approximately $40 \mathrm{mg}$ lignocaine and $0.2 \mathrm{mg}$ cetrimide) was applied to the back of the throat, and all patients received diazepam $10 \mathrm{mg}$ slowly intravenously. No other medications were given. All endoscopies were performed using the Olympus GIF P2.

\section{Results}

All patients were in sinus rhythm before the procedure. During intubation the heart rates varied between 65 and 150 beats per minute (bpm) (mean $103 \mathrm{bpm}$ ). This sinus tachycardia mainly related to anxiety. During extubation the heart rates had 
fallen significantly to between 115 and $60 \mathrm{bpm}$ (mean $93 \mathrm{bpm}$ ). The six episodes of sinus bradycardia (below $60 \mathrm{bpm}$ ) occurred in the younger patients (mean 23 years) and lasted from two to a maximum of six cardiac cycles. One patient had had three benign ventricular ectopic beats on intubation. No abnormalities of the ST segment or $\mathrm{T}$ waves were recorded.

\section{Discussion}

Our results do not suggest that significant ECG abnormalities occur in fit young men undergoing routine upper gastrointestinal endoscopy. Fletcher and colleagues ${ }^{2}$ who monitored 100 patients undergoing sigmoidoscopy found that the development of, or increase in, ectopic beats was significantly more frequent ( 40 per cent) in patients with heart disease, compared with patients without clinical evidence of heart disease (17 per cent). They were surprised to find that bradycardia, suggesting reflex increase in vagal tone, was the least frequently encountered change. However, in upper gastro-intestinal endoscopy, this was the only significant ECG change encountered by us.

Rhythm disturbances and repolarisation abnormalities during upper gastrointestinal endoscopy are much more common, and potenially serious, in patients with established heart disease. The rhythm disturbances include atrial tachycardia, atrial fibrillation, atrioventricular block, bundle branch blocks and nodal escape. Libor and colleagues ${ }^{3}$ reported on ECG disturbances in 102 patients with cardiorespiratory diseases (in which they include pulmonary emphysema, respiratory insufficiency and cardiac ischaemia). Of these the ECG during endoscopy showed rhythm disturbances in 21.2 per cent and repolarisation disturbances in 36.2 per cent. In conclusion potentially serious ECG changes during upper gastro-intestinal endoscopy may occur in patients with cardiorespiratory disease, but have not been found by us in fit young men.

\section{Acknowledgement}

Our thanks to Col D Cormack, L/RAMC for permission to study patients under his care.

\section{REFERENCES}

1. BENNET, J R (1979). Risks in the investigation and diagnosis of gastro-intestinal disease. The Practitioner 222, 231-235.

2. Fletcher, G F, Earnes, D L, Shuford, W F and Wenger, N K (1968). Electrocardiographic changes during routine sigmoidoscopy. Archives of Internal Medicine 122, 483-486.

3. Libor, Von J, Pocsai, G and IVANYI, J (1977). EKG-untersuchungen während der Ösophago-gastro-duodenoskopie. Zeittschrift für Gastroenterolgie 15, 293-299. 